\title{
Role of exercise on insulin sensitivity and beta-cell function: is exercise sufficient for the prevention of youth-onset type 2 diabetes?
}

Joon Young Kim, $\mathrm{PhD}$, Justin Y. Jeon, $\mathrm{PhD}^{2}$

${ }^{1}$ Department of Exercise Science, David B. Falk College of Sport and Human Dynamics, Syracuse University, Syracuse, NY, USA

2Department of Sport Industry Studies, Exercise Medicine Center for Diabetes and Cancer Patients, ICONS Yonsei University, Seoul, Korea
Received: 1 July, 2020

Revised: 9 August, 2020

Accepted: 19 August, 2020

Address for correspondence: Justin Y. Jeon, PhD

Department of Sport Industry Studies, Exercise Medicine Center for Diabetes and Cancer Patients, ICONS Yonsei University, 50 Yonseiro, Seodaemun-gu, Seoul 03722, Korea

Tel: +82-2-2123-6197

E-mail: jjeon@yonsei.ac.kr https://orcid.org/0000-0001-79784271
Parallel with the current pediatric obesity epidemic, the escalating rates of youthonset type 2 diabetes mellitus (T2DM) have become a major public health burden. Although lifestyle modification can be the first-line prevention for T2DM in youths, there is a lack of evidence to establish optimal specific exercise strategies for obese youths at high risk for T2DM. The purpose of this narrative review is to summarize the potential impact of exercise on 2 key pathophysiological risk factors for T2DM, insulin sensitivity and $\beta$-cell function, among obese youths. The studies cited are grouped by use of metabolic tests, i.e., direct and indirect measures of insulin sensitivity and $\beta$-cell function. In general, there are an increasing number of studies that demonstrate positive effects of aerobic exercise, resistance exercise, and the 2 combined on insulin sensitivity. However, a lack of evidence exists for the effect of any exercise modality on $\beta$-cell functional improvement. We also suggest a future direction for research into exercise medical prevention of youth-onset T2DM. These suggestions focus on the effects of exercise modalities on emerging biomarkers of T2DM risk.

Keywords: Childhood obesity, Type 2 diabetes, Exercise, Insulin resistance, Insulin secretion, Visceral fat, Inflammation, Biomarkers

\section{Introduction}

In parallel with the widespread pediatric obesity epidemic, youth-onset type 2 diabetes mellitus (T2DM) has emerged as an increasingly prevalent health condition in pediatrics. ${ }^{1-3)}$ Worldwide, the highest rate of youth-onset T2DM was observed in the United States in which the incidence increased from 9 to 12.5 cases per 100,000 between 2002 and 2012, ${ }^{2,3}$ accounting for one in 3 new cases of diabetes in youth. ${ }^{4}$ Similar to the natural history of T2DM in adults, ${ }^{5,6)}$ insulin resistance and pancreatic $\beta$-cell dysfunction are major pathophysiological biomarkers of youth-onset prediabetes and T2DM. ${ }^{7-9)}$ However, recent clinical observations demonstrated that youth-onset T2DM is characterized by rapid clinical deterioration, accelerated loss of $\beta$-cell function, rapid progression of complications, high therapeutic failure rates with decreased therapeutic response to insulin sensitizers (metformin, metformin plus rosiglitazone), and rapid progression to insulin dependence compared to adult-onset T2DM. ${ }^{7-11)}$ Moreover, obese youths with prediabetes exhibited 2-fold higher insulin resistance than equally obese adults with prediabetes indicating increased pathophysiological process severity prior to T2DM onset. ${ }^{12)}$ Considering the high therapeutic failure rates in obese youths with T2DM and given the high incidence of severe insulin resistance in obese youths with prediabetes, identification of appropriate T2DM prevention strategies for high-risk youths, i.e., obese and prediabetic youths, is essential.

Lifestyle modification can be the first-line treatment and/or prevention for T2DM in 
youths, ${ }^{13,14)}$ and physical inactivity is a major contributor to childhood obesity and related adverse health outcomes. ${ }^{15)}$ The 2nd edition of the Physical Activity Guidelines for Americans recommends that youths engage in both aerobic and musclestrengthening exercise to improve overall health. ${ }^{16)}$ For diabetes prevention/treatment in adults, the combination of aerobic and resistance exercise is suggested as an efficient strategy for improving glycemic control and insulin sensitivity. ${ }^{17,18)}$ A wealth of scientific and clinical evidence has allowed establishment of specific exercise strategies for diabetic and prediabetic adults. However, there is a lack of consistent data, despite an increasing number of randomized controlled trials in exercise intervention, to support specific exercise strategy guidelines for youths who are at high risk for T2DM. Additionally, only a few studies have described the effects of exercise on insulin sensitivity and $\beta$-cell function, 2 key pathophysiological components of T2DM. This paucity of data has hindered our current ability to identify the best diabetes prevention approach for youths.

For this reason, the purpose of this narrative review is to present recent evidence on the impact of exercise on insulin sensitivity and $\beta$-cell function among obese youths. We will mainly focus on exercise intervention studies in obese youths without diabetes that evaluated improvement of insulin resistance and $\beta$-cell function, biomarkers for T2DM. Because various measurement tools for insulin sensitivity/resistance and $\beta$-cell function have been used in the studies, the present review is organized by the measurement techniques. We then discuss future directions for facilitating the translation of pediatric exercise research into clinical practice to prevent the development of T2DM in youths.

\section{Exercise and direct measures of insulin sensitivity/resistance}

A core metabolic derangement from normal weight to obesity and from normal glucose tolerance to prediabetes to T2DM is insulin resistance. This resistance occurs at insulin-sensitive hepatic, adipose, and peripheral tissues in youths. ${ }^{19-21)} \mathrm{A}$ variety of measurement methodologies including hyperglycemiceuglycemic clamp, intravenous glucose tolerance test, and oral glucose tolerance test have been used to evaluate insulin sensitivity. ${ }^{22)}$

A study on 14 lean and 15 obese postpubertal adolescents assessed the effects of 12 weeks of aerobic exercise on insulin sensitivity calculated from the stable label intravenous glucose tolerance test. ${ }^{23)}$ In both lean and obese adolescents, peripheral insulin sensitivity (35\% and 59\%, respectively, all $P<0.05$ ) and hepatic insulin sensitivity (19\% and $23 \%$, respectively, all $P<0.01)$ increased after the exercise program, attesting to the beneficial effects of aerobic exercise on global insulin sensitivity. Bell et al. ${ }^{24)}$ studied the effects of eight weeks of circuit training consisting of aerobic exercises on 14 obese adolescents. This group analyzed the $\mathrm{M}_{(\mathrm{bm})}$ value, indicative of in vivo insulin sensitivity after accounting for lean body mass, calculated from the euglycemic-hyperinsulinemic clamp and found improvement of insulin sensitivity (pretraining $\mathrm{M}_{(\mathrm{lbm})}$

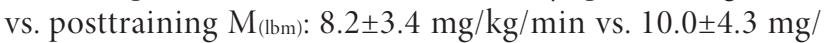
$\mathrm{kg} / \mathrm{min}, P=0.019)$ without changes in body mass index or percent body fat. Further, Davis et al. ${ }^{25)}$ demonstrated doseresponse benefits for insulin resistance and improvement of visceral adiposity in overweight/obese children. Matsuda index, representative of whole-body insulin sensitivity, measured from the oral glucose tolerance test was improved with a significant upward trend with exercise dose; greater improvement in the high aerobic exercise dose (40 $\mathrm{min} /$ day) group and the low aerobic exercise dose $(20 \mathrm{~min} /$ day) group than in the control group was demonstrated. Exercise was conducted for 13 weeks in that study. Similar beneficial effects of aerobic exercise were described in various interventions: lifestyle intervention with 6 months of aerobic exercise ${ }^{26)}$ and 12 weeks of a school-based aerobic physical activity program in Taiwan. ${ }^{27)}$ Furthermore, a recent study ${ }^{28)}$ examined the effectiveness of 3 exercise modalities, aerobic versus resistance versus the 2 combined, on hyperinsulinemic-euglycemic clamp-measured insulin sensitivity (expressed as whole-body insulin-stimulated glucose disposal [Rd]) in overweight/obese youths. All 3 exercise groups (i.e., aerobic alone $\left[180 \mathrm{~min} / \mathrm{wk}\right.$ at $50 \%-65 \%$ of peak $\left.\mathrm{VO}_{2}\right]$, resistance alone [ $180 \mathrm{~min} / \mathrm{wk}$ of weightlifting with $12-15 \mathrm{reps}$ per set], and aerobic and resistance exercise combined) were associated with significant improvement in Rd after completion of 20-22 weeks of the interventions. ${ }^{28)}$ Moreover, combined aerobic and resistance exercise and aerobic exercise alone were similarly beneficial, but were better than resistance exercise alone, in improving insulin sensitivity. ${ }^{28)}$

In contrast to the aforementioned studies, some studies reported no enhancement of insulin sensitivity measured by the frequently sampled intravenous glucose tolerance test after 6 months of high- $(70 \%-85 \%$ of heart rate reserve $)$ and moderate(40\%-55\% heart rate reserve) intensity endurance training in obese adolescents $^{29)}$ and after 16 weeks of multidisciplinary (nutrition education combined) intervention. ${ }^{30)}$ Further investigations are warranted to investigate the effects of exercise modalities on insulin sensitivity.

Lee et al. ${ }^{31)}$ examined the effect of 3 months of aerobic exercise or resistance exercise on insulin sensitivity in obese female and obese male ${ }^{32)}$ adolescents. In obese adolescent girls, only the groups with aerobic exercise showed improvement in peripheral insulin sensitivity $(\Delta 0.92 \pm 0.27 \mathrm{mg} / \mathrm{kg} / \mathrm{min}$ per $\mu \mathrm{U} /$ $\mathrm{mL}$ ) measured by 3-hour hyperinsulinemic-euglycemic clamp compared with the control group. ${ }^{29)}$ Interestingly, opposite results were observed in obese adolescent boys: only the groups with resistance exercise exhibited significant improvement in peripheral insulin sensitivity $(\Delta 0.8 \pm 0.2 \mathrm{mg} / \mathrm{kg} / \mathrm{min}$ per $\mu \mathrm{U} / \mathrm{mL})$ compared with the control group. ${ }^{32)}$ The observations in boys were in line with another study by Shaibi et al. ${ }^{33)}$ who conducted a 16-week intervention in overweight Latino adolescent boys. Significant enhancement of insulin sensitivity $\left(\Delta 0.9 \pm 0.1 \times 10^{-}\right.$ $4 / \mathrm{min} / \mu \mathrm{U} / \mathrm{mL}$ ) measured by frequently sampled intravenous glucose tolerance test was observed in the resistance exercise group compared with the control group. However, one study 
reported no gender difference in the effects of resistance exercise (12 weeks) in obese Hispanic youths. This study demonstrated that resistance exercise was effective in improving hepatic, but not peripheral, insulin sensitivity. ${ }^{34)}$

Additional investigations are needed to provide genderspecific resistance vs. aerobic exercise strategies for metabolic improvement interventions and to elucidate the mechanisms responsible for depot-specific (peripheral vs. hepatic vs. adipose tissue) insulin sensitivity improvement.

\section{Exercise and indirect measures of insulin sensitivity/resistance}

Invasive direct metabolic tests present a burden on participants, potentially causing low retention rates in exercise interventions. For this reason, fasting blood tests and tests for various indirect indicators of insulin sensitivity have been used in pediatric exercise research. The indirect indicator tests include tests for visceral adiposity and inflammation biomarkers such as adiponectin and leptin. Fasting insulin concentration alone and a homeostatic model assessment for insulin resistance (HOMA-IR) were widely used in pediatric obesity and T2DM research since those indicators have been validated against the gold-standard measure of insulin sensitivity. ${ }^{35}$ Some studies confirmed the effects of aerobic exercise, ${ }^{23,25,36-45)}$ aerobic and resistance exercise combined, ${ }^{46-49)}$ and multidisciplinary intervention ${ }^{26,27,50,51)}$ on improving fasting insulin and/or HOMA-IR. Savoye et al. ${ }^{41)}$ conducted a randomized controlled trial in obese youths examining short-term (6 months) and long-term (12 months) aerobic exercise intervention effects. Compared to the control group, the aerobic exercise group showed a significant decrease in fasting insulin ( $\Delta 1.7$ vs. $\Delta-6.5$ $\mu \mathrm{U} / \mathrm{mL})$ and HOMA-IR $(\Delta 0.33$ vs. $\Delta-1.51)$ at 6 months, and the improvements in fasting insulin $(\Delta 4.5$ vs. $\Delta-6.1 \mu \mathrm{U} / \mathrm{mL})$ and HOMA-IR ( $\Delta 0.90$ vs. $\Delta-1.52)$ remained at 12 months. ${ }^{41)}$ One study with 1 year of multidisciplinary intervention ${ }^{50)}$ consisting of nutritional, exercise, psychological, and clinical therapy had similar findings. Short-term (6 months) and long-term (12 months) effects of aerobic exercise on insulin resistance measured by fasting insulin were 23\% and 35\% decreases, respectively, compared to baseline, $P<0.05$; and, in obese boys, HOMA-IR experienced $20 \%$ and $35 \%$ decreases, respectively, compared to baseline, $P<0.05)$.

However, there is a lack of evidence that resistance exercise alone has beneficial effects on improving either fasting insulin $^{31-34)}$ or HOMA-IR. ${ }^{38,52,53)}$ Additionally, the superior effects of aerobic and resistance exercise combined over aerobic exercise alone on fasting insulin and HOMA-IR is still inconclusive. ${ }^{47,49,54)}$ After 12 months of exercise intervention, thepostpubertal obese youths in the combination of aerobic and resistance exercise group had lower fasting insulin and HOMA-IR while those in the aerobic exercise alone group did not show any significant improvement. ${ }^{49)}$ In another 12 months of exercise intervention study, both aerobic exercise alone and a combination of aerobic and resistance exercise were similarly effective in decreasing fasting insulin and HOMA-IR in postpubertal obese adolescents. ${ }^{47)}$ Last, despite an increasing number of studies supporting the effectiveness of exercise in reducing fasting insulin and/or HOMA-IR, other studies showed absences of positive effects of aerobic exercise, , $^{24,31,32,55-58)}$ combinations of aerobic and resistance exercise, ${ }^{38)}$ and multidisciplinary interventions. ${ }^{59,60)}$ The possible explanations for such inconsistent findings are heterogeneity of study designs (i.e., different dose/intensity of exercise intervention, diverse inclusion criteria with respect to glycemic status, Tanner stage, ethnicity, and sample size) and/or use of indirect measurements of insulin sensitivity. Shih and Kwok ${ }^{27)}$ reported that the impaired glucose tolerance with school physical activity training group members had more significant improvement in fasting insulin and HOMA-IR than the normal glucose tolerance counterpart. In addition, Kang et al. ${ }^{55)}$ found an ethnicity effect. Fasting insulin levels were higher in black obese youths than in white obese youths after aerobic exercise. Therefore, future studies using robust study designs consisting of various phenotypes are warranted .

Abdominal visceral adipose tissue (VAT) is an important determinant of insulin resistance across all age groups. ${ }^{61-63)}$ VAT is metabolically active with respect to lipid metabolism, and increased VAT can cause elevated free fatty acid flux to the liver resulting in insulin resistance. ${ }^{64,65)}$ Interestingly, VAT may differ between individuals with similar total body fat. ${ }^{66)}$ As such, VAT, which could be indicative of insulin sensitivity, has been widely evaluated in the exercise intervention studies as a means of effectiveness assessment. Aerobic exercise ${ }^{25,31,32,42,55,67,68)}$ and a combination of aerobic and resistance exercise $e^{47-49,54)}$ have been suggested to be effective in reducing VAT as measured by either computed tomography or magnetic resonance imaging. Some resistance exercise ${ }^{32}$ and multidisciplinary lifestyle interventions ${ }^{50,69)}$ also demonstrated VAT improvement. A 12-week aerobic exercise program was more effective in reducing VAT in obese adolescents $\left(54.7 \pm 6.0 \mathrm{~cm}^{2}\right.$ to $49.6 \pm 5.5$ $\left.\mathrm{cm}^{2}, P<0.05\right)$ than lean ones. ${ }^{42)}$ In addition, after a one-year multidisciplinary intervention, obese boys exhibited short-term and long-term VAT improvements (-23\% and $-26 \%$, respectively, all $P<0.05)$ with aerobic exercise; however, obese girls only exhibited the long-term effect $(-26 \%$ at 12 months, $P<0.05){ }^{50)}$

The efficacy of the combination of aerobic and resistance exercise over aerobic or resistance exercise alone in improving VAT requires further study. One study ${ }^{47)}$ reported that aerobic and resistance exercise combined was more effective in reducing VAT in obese adolescents after 12 months of the intervention, but other studies did not show any significant differences between aerobic and resistance combined and aerobic exercise alone groups after their intervention. ${ }^{49,54)}$ Whether resistance exercise alone is effective in reducing VAT in youths is unclear; the number of relevant studies is too small, and the results of those studies are too inconsistent to draw definite conclusions, ${ }^{70}$ Lee et al. ${ }^{32)}$ reported the positive effect of resistance exercise on reducing VAT in obese boys. Interestingly, when using a similar research design, those effects of resistance exercise on VAT were 
not observed in obese girls. ${ }^{31)}$ In addition, Van Der Heijden et $\mathrm{al}^{34)}$ also reported no significant effect of resistance exercise on improving VAT.

Last, the levels of circulating inflammation biomarkers adiponectin and leptin have been used in research as indicators of insulin sensitivity. There is a close relationship between insulin sensitivity/resistance and adiponectin and leptin levels across all age groups. ${ }^{71,72)}$ However, the effect of exercise on adiponectin level is controversial. Kim et al. ${ }^{36)}$ observed a significant increase $(\sim 10 \%)$ in adiponectin level among obese youths after 6 weeks of aerobic exercise. However, there was no significant improvement in adiponectin level after 12 weeks of lifestyle plus exercise intervention in obese girls ${ }^{40)}$ or after 12 weeks of aerobic exercise $(120 \mathrm{~min} / \mathrm{wk})$ intervention in overweight/obese girls. ${ }^{57)}$ Resistance training alone was not effective in improving adiponectin levels in obese youths after completion of a 12-week exercise intervention. The combination of aerobic and resistance exercise has been consistently shown to be effective in lowering adiponectin levels in obese adolescents $^{49)}$. This combination has a superior effect to aerobic exercise alone in improving adiponectin levels in short-term ${ }^{54}$ and long-term training. ${ }^{47)}$

A few of studies have examined the effect of exercise on changes in leptin level. Leptin level was significantly reduced after 12 weeks of aerobic exercise $e^{40,43)}$ or after 12 weeks of a lifestyle intervention that included 45 minutes of moderate to vigorous cardiovascular physical activity. ${ }^{60)}$ In postpubertal obese adolescents, both aerobic exercise alone and combined aerobic and resistance exercise were effective in reducing leptin levels after 6 months of training ${ }^{38)}$ compared to leisure physical activity $(\Delta 8.62 \pm 15.38 \mathrm{ng} / \mathrm{mL}$ and $\Delta 13.34 \pm 10.76 \mathrm{ng} /$ $\mathrm{mL}$, respectively, all $P<0.05)$. Additionally, Damaso et al. ${ }^{47)}$ observed that a combination of aerobic and resistance exercise was superior to aerobic exercise alone in reducing leptin levels in postpubertal obese adolescents after 12 months of exercise intervention.

Collectively, a variety of indirect measures of insulin sensitivity, including fasting insulin, HOMA-IR, VAT and inflammatory biomarkers, have been evaluated in pediatric exercise research. Although testing for these indicators of insulin sensitivity is cost effective and/or less invasive compared to the direct measures, inconsistent results among previous studies have been reported, presumably due to the nature of indirect measures. Therefore, comprehensive investigation of the relationship between specific exercise modalities (aerobic vs. resistance vs. the 2 combined) and each outcome measure is warranted. The identification of the optimal exercise regimen that yields significant improvement on indirect measures of insulin sensitivity will assist researchers, clinicians and exercise physiologists.

\section{Exercise and pancreatic $\beta$-cell function}

Given the pathophysiological importance of pancreatic $\beta$-cell function in the natural history of prediabetes and T2DM, i.e., loss of compensatory capacity of insulin secretion in the face of insulin resistance, ${ }^{5,6)} \beta$-cell functional improvement should be considered when exercise intervention is initiated for diabetes prevention/treatment. However, in contrast to the wealth of scientific studies regarding insulin sensitivity, little is known about potential effects of exercise on $\beta$-cell function. A variety of metabolic tests can be used to evaluate pancreatic $\beta$-cell function in insulin secretion and insulin secretion relative to insulin sensitivity.

Beta-cell function can be measured during an oral glucose tolerance test by using simple mathematical models, introducing insulinogenic index (indicative of early-phase insulin secretion), total area under the curve (AUC) of insulin response (indicative of hyperinsulinemia) during the test, and oral disposition index (DI=insulin sensitivity $\times$ insulin secretion). Shih and Kwok ${ }^{27)}$ examined the effects of their exercise program combined with physical education in overweight/obese male Taiwanese adolescents. After the 12-week exercise training, overweight/ obese boys showed significant increases in insulinogenic index (8.62 $\mu \mathrm{IU} / \mathrm{mM}$ vs. $11.40 \mu \mathrm{IU} / \mathrm{mM}$ ) and oral DI (5.84 vs. 12.77) and significant decreases in total insulin-AUC $(4.65 \mu \mathrm{IU} / \mathrm{mM}$ vs. $3.57 \mu \mathrm{IU} / \mathrm{mM}$ ), attesting that exercise training may improve pancreatic $\beta$-cell function. The beneficial effects of exercise on insulin-AUC is relatively consistent in aerobic exercise intervention. ${ }^{25,57)}$ Regardless of dose of aerobic exercise (i.e., 20 minutes vs. 40 minutes), overweight/obese adolescents showed significant decreases in insulin-AUC (adjusted mean difference, high dose vs. control: $-3.56[95 \%$ confidence interval $\{\mathrm{CI}\},-6.26$ to -0.85$] \times 10^{3} \mu \mathrm{U} / \mathrm{mL}$; low dose vs. control -2.96 [95\% CI, -5.69 to -0.22$] \times 10^{3} \mu \mathrm{U} / \mathrm{mL}$ ) compared to the control group. ${ }^{25)}$ Savoye et $\mathrm{al}^{26)}$ observed that lifestyle intervention that included aerobic exercise led to a significant decrease in insulin-AUC compared with the control group (data not shown). However, Suh et al. ${ }^{73)}$ reported no significant increase in insulinogenic index in any intervention groups over 12 weeks in overweight/obese children (aerobic vs. resistance vs. diet only). Furthermore, 2 studies of aerobic exercise intervention found significant improvement in $\mathrm{DI}^{25,27)}$ while 3 studies reported no improvement in DI after exercise intervention. ${ }^{26,32,59)}$ Davis et al. ${ }^{25)}$ observed that only a high-dose of aerobic exercise was effective in improving DI in obese youths compared to the control group (adjusted mean difference, high dose vs. control: 0.84 [95\% CI, 0.02 to 1.65], $P=0.04$ ); a low dose of aerobic exercise had no effect on improving DI (adjusted mean difference, low dose vs. control: 0.19 [ $95 \%$ CI, -0.63 to 1.02 ], $P=0.65$ ). Studies conducted on resistance exercise intervention did not report any significant improvement in DI compared to the baseline or control group. ${ }^{30,32,33,53)}$ Even with a more sophisticated metabolic test, i.e., frequently sampled intravenous glucose tolerance test, 4 studies reported that acute insulin release, representative of in vivo $\beta$-cell function, was not improved after aerobic exercise, ${ }^{59)}$ resistance exercise, ${ }^{33,53)}$ or the 2 combined. ${ }^{30)}$

Taken together, a potential improvement of $\beta$-cell function resulting from aerobic exercise is suggested. However, the limited number of studies are insufficient for us to conclude 
that exercise has beneficial effects on $\beta$-cell function. More pediatric research focusing on $\beta$-cell function with various exercise intensities/modalities is warranted.

\section{Summary and future directions}

This review summarized the effects of aerobic, resistance exercise, or combined exercise interventions, focusing on metabolic improvement rather than weight loss in the face of worldwide increasing prevalence of T2DM in obese youths. Table 1 lists the previous studies cited in this review. In general, there is an increasing number of studies demonstrating positive exercise effects on insulin sensitivity; however, a lack of evidence exists in relation to $\beta$-cell functional improvement. A potential explanation for such observations is that insulin sensitivity rather than secretion could be acutely improved in response to $\sim 12$ to 16 weeks of exercise intervention. A large cohort with a longer period of exercise training is needed to potentially demonstrate improved $\beta$-cell function. Currently, there are several challenges in making a solid conclusion on the beneficial effects of exercise on insulin sensitivity and $\beta$-cell function in youths: (1) not enough replicated studies with sufficient power in obese youths, (2) heterogeneity of the pediatric population in each study (i.e., different race, gender, and Tanner stage), (3) different length and dose of the exercise interventions with various modalities, and (4) a variety of measurement methodologies for insulin sensitivity and $\beta$-cell function used in each study. A carefully designed future study is needed to establish the occurrence of T2DM risk reduction in response to various exercise modalities in youths.

Last, we want to highlight the need for a simple, consistently reliable measurement tool for assessing the effects of exercise on prevention for T2DM. Exercise intervention requires effort on the part of participants, and invasive metabolic testing such as clamp and intravenous glucose tolerance test is not ideal. Various indices derived from the oral glucose tolerance test (Matsuda index, insulinogenic index, and oral DI) and fasting biomarkers (HOMA-IR, insulin, adiponectin level, and leptin level) have been widely used in pediatric exercise studies. Increasing attention has been given to novel biomarkers in the assessment of youth-onset T2DM. These biomarkers are derived from oral glucose tolerance testing; therefore, consideration of the following measures in order to enhance the capability of testing effectiveness of exercise on T2DM risk is necessary: (1) glucoseresponse curve, ${ }^{74-76)}$ (2) 1-hour glucose concentration, ${ }^{77-79)}$ and (3) time-to-glucose-peak. ${ }^{80-82)}$ Those emerging biomarkers have been recently examined and considered as sensitive and early indicators of T2DM risk, indicative of both insulin sensitivity and $\beta$-cell function, in obese youths. Assessing those novel biomarkers in response to any exercise intervention is essential. ${ }^{83)}$ This research will form the launching pad for new discoveries that advance scientific knowledge in exercise science as these biomarkers can be used as identification criteria for obese youths in desperate need of exercise intervention for T2DM and as an evaluation tool for testing the effectiveness of exercise modalities.

\section{Conflicts of interest}

No potential conflict of interest relevant to this article was reported.

Table 1. List of references by exercise modalities and existence/absence of significant results

\begin{tabular}{|c|c|c|c|c|c|c|}
\hline Variable & AE only & RE only & $\begin{array}{c}\text { Combination of } \\
\mathrm{AE} \text { and RE }\end{array}$ & $\begin{array}{l}\text { Lifestyle } \\
\text { intervention }\end{array}$ & $\begin{array}{c}\text { Studies that } \\
\text { showed significant } \\
\text { improvement }\end{array}$ & $\begin{array}{c}\text { Studies that showed } \\
\text { no significant } \\
\text { change }\end{array}$ \\
\hline $\begin{array}{l}\text { In vivo insulin } \\
\text { sensitivity }\end{array}$ & $(23-\mathbf{2 5}, 27-29,31,32)$ & $(28,30-34)$ & $(\mathbf{2 8}, 30,53)$ & (26) & $(23-28,31-34)$ & $(29-31,34,53)$ \\
\hline HOMA-IR & $\begin{array}{c}(27,36-41,42,44 \\
45,47,49,54,57,58)\end{array}$ & $(30,38,52,53)$ & $(30,46-49,54)$ & $(26,50,51,60)$ & $\begin{array}{c}(26,27,36,37,39-42 \\
45-51,54)\end{array}$ & $\begin{array}{c}(30,38,44,52,53,57 \\
58,60)\end{array}$ \\
\hline Fasting Insulin & $\begin{array}{c}(23-25,27,31,32,36- \\
44,47,49,54-58)\end{array}$ & $(30-34,38,52,53)$ & $(30,46-49,54)$ & $(26,50,51,59,60)$ & $\begin{array}{c}(23,25-27,36,37,39- \\
44,46-51,54)\end{array}$ & $\begin{array}{c}(\mathbf{2 4}, 30-34,38,52,53 \\
55-60)\end{array}$ \\
\hline VAT & $\begin{array}{c}(25,29,31,32,42,47 \\
49,54,55,57,67,68 \\
70)\end{array}$ & $(31,32,34,70)$ & $(47-49,54,70)$ & $(50,69)$ & $\begin{array}{c}(25,31,32,42,47-50 \\
54,55,67-69)\end{array}$ & $(29,34,57,70)$ \\
\hline Adiponectin & $\begin{array}{c}(23,36,40,47,49,54 \\
57,58)\end{array}$ & (34) & $(47,49,54)$ & & $(36,47,49,54)$ & $(23,34,40,57,58)$ \\
\hline leptin & $(23, \mathbf{3 8}, 40,43,47)$ & (34) & $(38,47)$ & (60) & $(38,40,43,47,60)$ & $(23,34)$ \\
\hline $\begin{array}{l}\text { Insulinogenic } \\
\text { index }\end{array}$ & $(27,73)$ & (73) & & & $(27)$ & (73) \\
\hline Insulin-AUC & $(25,27,31,57,73)$ & $(31,73)$ & & (26) & $(25-27,57,73)$ & (31) \\
\hline DI & $(27,32)$ & $(30,32,33,53)$ & (30) & $(26,59)$ & (27) & $(26,30,32,33,53,59)$ \\
\hline AIR & & $(30,33,53)$ & (30) & (59) & & $(30,33,53,59)$ \\
\hline
\end{tabular}

$A E$, aerobic exercise; $R E$, resistance exercise; HOMA-IR, homeostatic model assessment for insulin resistance; VAT, visceral adipose tissue;

$A U C$, area under the curve; DI, disposition index; AIR, acute insulin release.

References recommended by authors indicated in bold. 


\section{References}

1. Dabelea D, Mayer-Davis EJ, Saydah S, Imperatore G, Linder B, Divers J, et al. Prevalence of type 1 and type 2 diabetes among children and adolescents from 2001 to 2009. JAMA 2014;311:1778-86.

2. Mayer-Davis EJ, Dabelea D, Lawrence JM. Incidence trends of type 1 and type 2 diabetes among youths, 2002-2012. N Engl J Med 2017;377:301.

3. Fazeli Farsani S, van der Aa MP, van der Vorst MM, Knibbe CA, de Boer A. Global trends in the incidence and prevalence of type 2 diabetes in children and adolescents: a systematic review and evaluation of methodological approaches. Diabetologia 2013;56:1471-88.

4. Copeland KC, Silverstein J, Moore KR, Prazar GE, Raymer T, Shiffman RN, et al. Management of newly diagnosed type 2 Diabetes Mellitus (T2DM) in children and adolescents. Pediatrics 2013;131:364-82.

5. Defronzo RA. Banting lecture. From the triumvirate to the ominous octet: a new paradigm for the treatment of type 2 diabetes mellitus. Diabetes 2009;58:773-95.

6. Kahn SE. The relative contributions of insulin resistance and beta-cell dysfunction to the pathophysiology of type 2 diabetes. Diabetologia 2003;46:3-19.

7. Lynch J, El L, Fisher L, Gidding SS, Laffel L, Libman I, et al. Rapid rise in hypertension and nephropathy in youth with type 2 diabetes: the TODAY clinical trial. Diabetes Care 2013;36:1735-41.

8. Weinstock RS, Caprio S, Copeland KC, Gidding SS, Hirst K, Katz LL, et al. Lipid and inflammatory cardiovascular risk worsens over 3 years in youth with type 2 diabetes: the TODAY clinical trial. Diabetes Care 2013;36:1758-64.

9. Levitsky LL, Danis RP, Drews KL, Tamborlane WV, Haymond W, Laffel L, et al. Retinopathy in youth with type 2 diabetes participating in the TODAY clinical trial. Diabetes Care 2013;36:1772-4.

10. Hannon TS, Arslanian SA. The changing face of diabetes in youth: lessons learned from studies of type 2 diabetes. Ann N Y Acad Sci 2015;1353:113-37.

11. Zeitler P, Hirst K, Pyle L, Linder B, Copeland K, Arslanian S, et al. A clinical trial to maintain glycemic control in youth with type 2 diabetes. N Engl J Med 2012;366:2247-56.

12. Arslanian S, Kim JY, Nasr A, Bacha F, Tfayli H, Lee S, et al. Insulin sensitivity across the lifespan from obese adolescents to obese adults with impaired glucose tolerance: who is worse off? Pediatr Diabetes 2018;19:20511.

13. McGavock J, Dart A, Wicklow B. Lifestyle therapy for the treatment of youth with type 2 diabetes. Curr Diab Rep 2015; 15:568.

14. Ho M, Garnett SP, Baur LA, Burrows T, Stewart L, Neve $\mathrm{M}$, et al. Impact of dietary and exercise interventions on weight change and metabolic outcomes in obese children and adolescents: a systematic review and meta-analysis of randomized trials. JAMA Pediatr 2013;167:759-68.
15. Daniels SR, Arnett DK, Eckel RH, Gidding SS, Hayman LL, Kumanyika S, et al. Overweight in children and adolescents: pathophysiology, consequences, prevention, and treatment. Circulation 2005;111:1999-2012.

16. US Department of Health and Human Services. Physical activity guidelines for Americans. 2nd ed. Wasington, DC: US Dept of Health and Human Services, 2018.

17. Church TS, Blair SN, Cocreham S, Johannsen N, Johnson W, Kramer K, et al. Effects of aerobic and resistance training on hemoglobin A1c levels in patients with type 2 diabetes: a randomized controlled trial. JAMA 2010;304:2253-62.

18. Davidson LE, Hudson R, Kilpatrick K, Kuk JL, McMillan $\mathrm{K}$, Janiszewski PM, et al. Effects of exercise modality on insulin resistance and functional limitation in older adults: a randomized controlled trial. Arch Intern Med 2009;169:122-31.

19. Levy-Marchal C, Arslanian S, Cutfield W, Sinaiko A, Druet C, Marcovecchio ML, et al. Insulin Resistance in Children Consensus Conference G. Insulin resistance in children: consensus, perspective, and future directions. J Clin Endocrinol Metab 2010;95:5189-98.

20. Bacha F, Gungor N, Lee S, Arslanian SA. In vivo insulin sensitivity and secretion in obese youth: what are the differences between normal glucose tolerance, impaired glucose tolerance, and type 2 diabetes? Diabetes Care 2009;32:100-5.

21. Kim JY, Bacha F, Tfayli H, Michaliszyn SF, Yousuf S, Arslanian S. Adipose tissue insulin resistance in youth on the spectrum from normal weight to obese and from normal glucose tolerance to impaired glucose tolerance to type 2 diabetes. Diabetes Care 2019;42:265-72.

22. Cobelli C, Toffolo GM, Dalla Man C, Campioni M, Denti $\mathrm{P}$, Caumo A, et al. Assessment of beta-cell function in humans, simultaneously with insulin sensitivity and hepatic extraction, from intravenous and oral glucose tests. Am J Physiol Endocrinol Metab 2007;293:E1-15.

23. van der Heijden GJ, Toffolo G, Manesso E, Sauer PJ, Sunehag AL. Aerobic exercise increases peripheral and hepatic insulin sensitivity in sedentary adolescents. J Clin Endocrinol Metab 2009;94:4292-99.

24. Bell LM, Watts K, Siafarikas A, Thompson A, Ratnam N, Bulsara $\mathrm{M}$, et al. Exercise alone reduces insulin resistance in obese children independently of changes in body composition. J Clin Endocrinol Metab 2007;92:4230-35.

25. Davis CL, Pollock NK, Waller JL, Allison JD, Dennis BA, Bassali R, et al. Exercise dose and diabetes risk in overweight and obese children: a randomized controlled trial. JAMA 2012;308:1103-12.

26. Savoye M, Caprio S, Dziura J, Camp A, Germain G, Summers C, et al. Reversal of early abnormalities in glucose metabolism in obese youth: results of an intensive lifestyle randomized controlled trial. Diabetes Care 2014;37:317-24.

27. Shih KC, Kwok CF. Exercise reduces body fat and improves insulin sensitivity and pancreatic beta-cell function in overweight and obese male Taiwanese adolescents. BMC Pediatr 2018;18:80. 
28. Lee S, Libman I, Hughan K, Kuk JL, Jeong JH, Zhang D, et al. Effects of exercise modality on insulin resistance and ectopic fat in adolescents with overweight and obesity: a randomized clinical trial. J Pediatr 2019;206:91-98.e1.

29. Hay J, Wittmeier K, MacIntosh A, Wicklow B, Duhamel T, Sellers E, et al. Physical activity intensity and type 2 diabetes risk in overweight youth: a randomized trial. Int J Obes 2016;40:607-14.

30. Davis JN, Tung A, Chak SS, Ventura EE, Byrd-Williams CE, Alexander KE, et al. Aerobic and strength training reduces adiposity in overweight Latina adolescents. Med Sci Sports Exerc 2009;41:1494-503.

31. Lee S, Deldin AR, White D, Kim Y, Libman I, RiveraVega M, et al. Aerobic exercise but not resistance exercise reduces intrahepatic lipid content and visceral fat and improves insulin sensitivity in obese adolescent girls: a randomized controlled trial. Am J Physiol Endocrinol Metab 2013;305:E1222-9.

32. Lee S, Bacha F, Hannon T, Kuk JL, Boesch C, Arslanian S. Effects of aerobic versus resistance exercise without caloric restriction on abdominal fat, intrahepatic lipid, and insulin sensitivity in obese adolescent boys: a randomized, controlled trial. Diabetes 2012;61:2787-95.

33. Shaibi GQ, Cruz ML, Ball GD, Weigensberg MJ, Salem GJ, Crespo NC, et al. Effects of resistance training on insulin sensitivity in overweight Latino adolescent males. Med Sci Sports Exerc 2006;38:1208-15.

34. Van Der Heijden GJ, Wang ZJ, Chu Z, Toffolo G, Manesso E, Sauer PJ, et al. Strength exercise improves muscle mass and hepatic insulin sensitivity in obese youth. Med Sci Sports Exerc 2010;42:1973-80.

35. George L, Bacha F, Lee S, Tfayli H, Andreatta E, Arslanian S. Surrogate estimates of insulin sensitivity in obese youth along the spectrum of glucose tolerance from normal to prediabetes to diabetes. J Clin Endocrinol Metab 2011;96:2136-45.

36. Kim ES, Im JA, Kim KC, Park JH, Suh SH, Kang ES, et al. Improved insulin sensitivity and adiponectin level after exercise training in obese Korean youth. Obesity 2007;15:3023-30.

37. Lee KJ, Shin YA, Lee KY, Jun TW, Song W. Aerobic exercise training-induced decrease in plasma visfatin and insulin resistance in obese female adolescents. Int J Sport Nutr Exerc Metab 2010;20:275-81.

38. Ackel-D'Elia C, Carnier J, Bueno CR Jr, Campos RM, Sanches PL, Clemente AP, et al. Effects of different physical exercises on leptin concentration in obese adolescents. Int J Sports Med 2014;35:164-71.

39. Meyer AA, Kundt G, Lenschow U, Schuff-Werner P, Kienast W. Improvement of early vascular changes and cardiovascular risk factors in obese children after a sixmonth exercise program. J Am Coll Cardiol 2006;48:186570.

40. Park TG, Hong HR, Lee J, Kang HS. Lifestyle plus exercise intervention improves metabolic syndrome markers without change in adiponectin in obese girls. Ann Nutr
Metab 2007;51:197-203.

41. Savoye M, Shaw M, Dziura J, Tamborlane WV, Rose P, Guandalini C, et al. Effects of a weight management program on body composition and metabolic parameters in overweight children: a randomized controlled trial. JAMA 2007;297:2697-704.

42. van der Heijden GJ, Wang ZJ, Chu ZD, Sauer PJ, Haymond MW, Rodriguez LM, et al. A 12-week aerobic exercise program reduces hepatic fat accumulation and insulin resistance in obese, Hispanic adolescents. Obesity 2010;18:384-90.

43. Karacabey K. The effect of exercise on leptin, insulin, cortisol and lipid profiles in obese children. J Int Med Res 2009;37:1472-8.

44. Leite N, Carvalho HM, Padez C, Lopes WA, Milano GE, Radominski RB, et al. Age and menarcheal status do not influence metabolic response to aerobic training in overweight girls. Diabetol Metab Syndr 2013;5:7.

45. Balagopal P, George D, Patton N, Yarandi H, Roberts WL, Bayne E, et al. Lifestyle-only intervention attenuates the inflammatory state associated with obesity: a randomized controlled study in adolescents. J Pediatr 2005;146:342-8.

46. Chang C, Liu W, Zhao X, Li S, Yu C. Effect of supervised exercise intervention on metabolic risk factors and physical fitness in Chinese obese children in early puberty. Obes Rev 2008;9 Suppl 1:135-41.

47. Damaso AR, da Silveira Campos RM, Caranti DA, de Piano A, Fisberg M, Foschini D, et al. Aerobic plus resistance training was more effective in improving the visceral adiposity, metabolic profile and inflammatory markers than aerobic training in obese adolescents. J Sports Sci 2014;32:1435-45.

48. Davis JN, Gyllenhammer LE, Vanni AA, Meija M, Tung A, Schroeder ET, et al. Startup circuit training program reduces metabolic risk in Latino adolescents. Med Sci Sports Exerc 2011;43:2195-203.

49. de Mello MT, de Piano A, Carnier J, Sanches Pde L, Correa FA, Tock L, et al. Long-term effects of aerobic plus resistance training on the metabolic syndrome and adiponectinemia in obese adolescents. J Clin Hypertens (Greenwich) 2011;13:343-50.

50. Caranti DA, de Mello MT, Prado WL, Tock L, Siqueira KO, de Piano A, et al. Short- and long-term beneficial effects of a multidisciplinary therapy for the control of metabolic syndrome in obese adolescents. Metabolism 2007;56:1293300.

51. Kelishadi R, Hashemi M, Mohammadifard N, Asgary S, Khavarian N. Association of changes in oxidative and proinflammatory states with changes in vascular function after a lifestyle modification trial among obese children. Clin Chem 2008;54:147-53.

52. Benson AC, Torode ME, Fiatarone Singh MA. The effect of high-intensity progressive resistance training on adiposity in children: a randomized controlled trial. Int J Obes 2008;32:1016-27.

53. Davis JN, Kelly LA, Lane CJ, Ventura EE, Byrd-Williams CE, 
Alexandar KA, et al. Randomized control trial to improve adiposity and insulin resistance in overweight Latino adolescents. Obesity 2009;17:1542-8.

54. Inoue DS, De Mello MT, Foschini D, Lira FS, De Piano Ganen A, Da Silveira Campos RM, et al. Linear and undulating periodized strength plus aerobic training promote similar benefits and lead to improvement of insulin resistance on obese adolescents. J Diabetes Complications 2015;29:258-64.

55. Kang HS, Gutin B, Barbeau P, Owens S, Lemmon CR, Allison J, et al. Physical training improves insulin resistance syndrome markers in obese adolescents. Med Sci Sports Exerc 2002;34:1920-7.

56. Kelly AS, Wetzsteon RJ, Kaiser DR, Steinberger J, Bank AJ, Dengel DR. Inflammation, insulin, and endothelial function in overweight children and adolescents: the role of exercise. J Pediatr 2004;145:731-6.

57. Nassis GP, Papantakou K, Skenderi K, Triandafillopoulou M, Kavouras SA, Yannakoulia M, et al. Aerobic exercise training improves insulin sensitivity without changes in body weight, body fat, adiponectin, and inflammatory markers in overweight and obese girls. Metabolism 2005;54:1472-9.

58. Murphy EC, Carson L, Neal W, Baylis C, Donley D, Yeater R. Effects of an exercise intervention using Dance Dance Revolution on endothelial function and other risk factors in overweight children. Int J Pediatr Obes 2009;4:205-14.

59. Rosenbaum M, Nonas C, Weil R, Horlick M, Fennoy I, Vargas I, et al. School-based intervention acutely improves insulin sensitivity and decreases inflammatory markers and body fatness in junior high school students. J Clin Endocrinol Metab 2007;92:504-8.

60. Monzavi R, Dreimane D, Geffner ME, Braun S, Conrad B, Klier M, et al. Improvement in risk factors for metabolic syndrome and insulin resistance in overweight youth who are treated with lifestyle intervention. Pediatrics 2006;117:e1111-8.

61. Lee S, Gungor N, Bacha F, Arslanian S. Insulin resistance: link to the components of the metabolic syndrome and biomarkers of endothelial dysfunction in youth. Diabetes Care 2007;30:2091-7.

62. Weiss R, Dufour S, Taksali SE, Tamborlane WV, Petersen KF, Bonadonna RC, et al. Prediabetes in obese youth: a syndrome of impaired glucose tolerance, severe insulin resistance, and altered myocellular and abdominal fat partitioning. Lancet 2003;362:951-7.

63. Preis SR, Massaro JM, Robins SJ, Hoffmann U, Vasan RS, Irlbeck T, et al. Abdominal subcutaneous and visceral adipose tissue and insulin resistance in the Framingham heart study. Obesity 2010;18:2191-8.

64. Wajchenberg BL. Subcutaneous and visceral adipose tissue: their relation to the metabolic syndrome. Endocr Rev 2000;21:697-738.

65. Ibrahim MM. Subcutaneous and visceral adipose tissue: structural and functional differences. Obes Rev 2010;11:118 .
66. Lebovitz HE, Banerji MA. Point: visceral adiposity is causally related to insulin resistance. Diabetes Care 2005;28:2322-5.

67. Owens S, Gutin B, Allison J, Riggs S, Ferguson M, Litaker M, et al. Effect of physical training on total and visceral fat in obese children. Med Sci Sports Exerc 1999;31:143-8.

68. Gutin B, Barbeau P, Owens S, Lemmon CR, Bauman M, Allison J, et al. Effects of exercise intensity on cardiovascular fitness, total body composition, and visceral adiposity of obese adolescents. Am J Clin Nutr 2002;75:818-26.

69. Barbeau P, Johnson MH, Howe CA, Allison J, Davis CL, Gutin B, et al. Ten months of exercise improves general and visceral adiposity, bone, and fitness in black girls. Obesity 2007; 15:2077-85.

70. Alberga AS, Prud'homme D, Kenny GP, Goldfield GS, Hadjiyannakis S, Gougeon R, et al. Effects of aerobic and resistance training on abdominal fat, apolipoproteins and high-sensitivity C-reactive protein in adolescents with obesity: the HEARTY randomized clinical trial. Int J Obes 2015;39:1494-500.

71. Koebnick C, Roberts CK, Shaibi GQ, Kelly LA, Lane CJ, Toledo-Corral CM, et al. Adiponectin and leptin are independently associated with insulin sensitivity, but not with insulin secretion or beta-cell function in overweight Hispanic adolescents. Horm Metab Res 2008;40:708-12.

72. Umeno A, Yoshino K, Hashimoto Y, Shichiri M, Kataoka M, Yoshida Y. Multi-biomarkers for early detection of type 2 diabetes, including 10- and 12-(Z,E)-hydroxyoctadecadienoic acids, insulin, leptin, and adiponectin. PLoS One 2015;10:e130971.

73. Suh S, Jeong IK, Kim MY, Kim YS, Shin S, Kim SS, et al. Effects of resistance training and aerobic exercise on insulin sensitivity in overweight korean adolescents: a controlled randomized trial. Diabetes Metab J 2011;35:418-26.

74. Kim JY, Coletta DK, Mandarino LJ, Shaibi GQ. Glucose response curve and type 2 diabetes risk in Latino adolescents. Diabetes Care 2012;35:1925-30.

75. Kim JY, Michaliszyn SF, Nasr A, Lee S, Tfayli H, Hannon $\mathrm{T}$, et al. The shape of the glucose response curve during an oral glucose tolerance test heralds biomarkers of type 2 diabetes risk in obese youth. Diabetes Care 2016;39:1431-9.

76. Arslanian S, El Ghormli L, Kim JY, Bacha F, Chan C, Ismail $\mathrm{HM}$, et al. The shape of the glucose response curve during an oral glucose tolerance test: forerunner of heightened glycemic failure rates and accelerated decline in beta-cell function in TODAY. Diabetes Care 2019;42:164-72.

77. Tfayli H, Lee SJ, Bacha F, Arslanian S. One-hour plasma glucose concentration during the OGTT: what does it tell about beta-cell function relative to insulin sensitivity in overweight/obese children? Pediatr Diabetes 2011;12:5729.

78. Kim JY, Goran MI, Toledo-Corral CM, Weigensberg MJ, Choi M, Shaibi GQ. One-hour glucose during an oral glucose challenge prospectively predicts beta-cell deterioration and prediabetes in obese Hispanic youth. Diabetes Care 2013;36:1681-6. 
79. Kim JY, Goran MI, Toledo-Corral CM, Weigensberg MJ, Shaibi GQ. Comparing glycemic indicators of prediabetes: a prospective study of obese Latino Youth. Pediatr Diabetes 2015;16:640-3.

80. Chung ST, Ha J, Onuzuruike AU, Kasturi K, Galvan-De La Cruz M, Bingham BA, et al. Time to glucose peak during an oral glucose tolerance test identifies prediabetes risk. Clin Endocrinol (Oxf) 2017;87:484-91.

81. Cree-Green M, Xie D, Rahat H, Garcia-Reyes Y, Bergman $\mathrm{BC}$, Scherzinger A, et al. Oral glucose tolerance test glucose peak time is most predictive of prediabetes and hepatic steatosis in obese girls. J Endocr Soc 2018;2:547-62.

82. Kim JY, Tfayli H, Bacha F, Lee S, Michaliszyn SF, Yousuf $\mathrm{S}$, et al. Beta-cell function, incretin response, and insulin sensitivity of glucose and fat metabolism in obese youth: relationship to OGTT-time-to-glucose-peak. Pediatr Diabetes 2020;21:18-27.

83. Shaibi GQ, Ryder JR, Kim JY, Barraza E. Exercise for obese youth: refocusing attention from weight loss to health gains. Exerc Sport Sci Rev 2015;43:41-7. 